\title{
Resistência Natural de Quatro Espécies Florestais Submetidas a Ensaio com Fungos Apodrecedores
}

\author{
Douglas Edson Carvalho' ${ }^{1}$, Elio José Santini², \\ Fernando Nunes Gouveia ${ }^{3}$, Márcio Pereira da Rocha ${ }^{1}$
}

${ }^{1}$ Centro de Ciências Florestais e da Madeira, Universidade Federal do Paraná - UFPR, Curitiba/PR, Brasil ${ }^{2}$ Departamento de Ciências Florestais, Universidade Federal de Santa Maria - UFSM, Santa Maria/RS, Brasil ${ }^{3}$ Laboratório de Produtos Florestais, Serviço Florestal Brasileiro, Brasília/DF, Brasil

\begin{abstract}
RESUMO
Este estudo teve como objetivo avaliar a durabilidade natural das madeiras de Eucalyptus dunnii, Eucalyptus robusta, Eucalyptus tereticornis e Hovenia dulcis submetidas ao ensaio de apodrecimento acelerado em laboratório com os fungos Gloeophyllum trabeum, causador de podridão parda; e Trametes versicolor, causador de podridão branca. As amostras permaneceram durante 12 semanas em contato com os fungos e após calcularam-se as porcentagens de perda de massa, classificadas quanto ao grau de resistência natural e avaliadas quanto ao índice de susceptibilidade ao ataque. As médias dos resultados foram comparadas pelo teste de Tukey a 5\% de significância. A madeira de Eucalyptus robusta foi classificada como resistente e Hovenia dulcis como não resistente para ambos os fungos. O índice de susceptibilidade ao ataque indicou que as espécies estudadas apresentaram valores aceitáveis, sendo mais resistentes ao ataque dos fungos em relação às espécies de referência (Pinus sp.; Cecropia sp.).
\end{abstract}

Palavras-chave: biodeterioração da madeira, perda de massa, durabilidade natural.

\section{Natural Resistance of Four Forest Species Submitted to Test with Decay Fungi}

\begin{abstract}
This study aimed to evaluate the natural durability of Eucalyptus dunnii, Eucalyptus robusta, Eucalyptus tereticornis and Hovenia dulcis woods subjected to accelerated testing in laboratory with rotting fungi Gloeophyllum trabeum, causer of brown rot; and Trametes versicolor, causer of white rot. The samples remained 12 weeks in contact with the fungi, after that, we calculated the percentages of mass loss, classified according to the degree of natural resistance and assessed according to the rate of susceptibility to attack. The averages of the results were compared by the Tukey test at 5\% significance level. Eucalyptus robusta wood was classified as resistant and Hovenia dulcis wood was classified as non-resistant to both fungi. The index of susceptibility to attack indicated that the species studied present acceptable values and that they are more resistant to the attack of fungi compared with reference species (Pinus sp.; Cecropia sp.)
\end{abstract}

Keywords: biodeterioration of wood, mass loss, natural durability. 


\section{INTRODUÇÃO}

Com a informação da heterogeneidade das espécies florestais sabe-se que estas possuem variações quanto a sua durabilidade natural, estando sujeitas à ação de agentes biodeterioradores da madeira, causando-lhes danos e consequentemente prejuízos, afetando suas condições de uso e somente conhecendo os aspectos biológicos, físicos, químicos e mecânicos que a danificam pode-se inferir sob sua utilização racional. Em virtude da sua estrutura anatômica e constituição química, a madeira está sujeita ao ataque de vários organismos deterioradores. Barillari (2002) afirmou que os fungos são os principais responsáveis pela destruição de produtos à base de madeira, como postes, dormentes e cercas, causando grandes prejuízos econômicos.

Segundo Santini (1988), o conteúdo das células parenquimáticas de certas espécies, como amidos, proteínas e açúcares, é muito procurado por fungos e insetos como alimento, o que explica sua maior susceptibilidade à ação destes organismos. Para Costa (2003), os agentes biológicos deterioradores uma vez instalados na madeira comprometem sua resistência mecânica e, de maneira geral, sempre foram os principais responsáveis pelas grandes perdas nos produtos e subprodutos de madeira.

Paes (2002) afirmou que a resistência natural da madeira à deterioração é a aptidão inerente à espécie de resistir à ação de agentes deterioradores, principalmente os biológicos. Alguns dos fatores inerentes à madeira relacionam-se com sua durabilidade, conforme citado por Walker (2006), em que a durabilidade natural da madeira está relacionada, principalmente, com a concentração de extrativos fenólicos (taninos, polifenóis, estilbenos, lignanas e flavonoides). Espécies com composições tóxicas aos organismos biodeterioradores refletem na sua durabilidade natural, consequentemente terão preferência em relação a espécies consideradas não resistentes, evitando inconvenientes do uso de produtos químicos e até mesmo substituição de peças deterioradas.

Nesse sentido, este estudo teve como objetivo avaliar a durabilidade natural das madeiras de Eucalyptus dunnii, Eucalyptus robusta, Eucalyptus tereticornis e Hovenia dulcis submetidas ao ensaio de apodrecimento acelerado em laboratório com os fungos Gloeophyllum trabeum, causador de podridão parda; e Trametes versicolor, causador de podridão branca.

\section{MATERIAL E MÉTODOS}

No estudo foram utilizadas madeiras de cerne de Eucalyptus dunnii Maiden, Eucalyptus robusta $\mathrm{Sm}$, Eucalyptus tereticornis Sm e Hovenia dulcis Thunberg, com idades aproximadas de 35 anos. O ensaio de apodrecimento acelerado foi conduzido no Setor de Biodegradação e Preservação da Madeira, do Laboratório de Produtos Florestais (LPF) do Serviço Florestal Brasileiro, em Brasília, DF, segundo a ASTM D 2017 (ASTM, 2005). A massa específica aparente a $12 \%$ de umidade foi determinada a partir da massa e volume das amostras tomados após estabilização da umidade de equilíbrio das mesmas em câmara climatizada à temperatura de $20 \pm 2{ }^{\circ} \mathrm{C}$ e umidade relativa de $65 \pm 5 \%$.

As amostras, confeccionadas nas dimensões de $2,0 \times 2,0 \times 1,0 \mathrm{~cm}$ (comprimento, largura e espessura), foram secas em estufa com circulação forçada de ar a $50 \pm 2{ }^{\circ} \mathrm{C}$ até massa constante. Para pesagem utilizou-se balança de 0,0001 g de precisão. Antes da exposição aos fungos as amostras foram esterilizadas em autoclave a $127^{\circ} \mathrm{C}$ por 40 minutos.

Foram empregados os fungos xilófagos Gloeophyllum trabeum (Persoon ex Fries) Murrill causador de podridão parda e Trametes versicolor (Linnaeus ex Fries) Pilát causador de podridão branca. Os fungos foram repicados em meio de cultura malte líquido e levados à incubadora $\left(26 \pm 2{ }^{\circ} \mathrm{C}\right.$ e $70 \pm 5 \%$ de umidade relativa $)$ até o micélio recobrir totalmente a superfície do meio (três semanas). No momento da inoculação o micélio foi fragmentado em um liquidificador doméstico para facilitar o trabalho. Todas as operações de manipulação de fungos foram efetuadas assepticamente em capela de fluxo laminar.

Os ensaios foram montados em frascos de vidro transparente com boca larga, tampa rosqueável, capacidade de $250 \mathrm{~mL}$, contendo $90 \mathrm{~g}$ de solo (horizonte B) peneirado (abertura de malha de $2 \mathrm{~mm}$ ) livre de matéria orgânica. O solo recebeu prévia adição de calcário para elevar o $\mathrm{pH}$ a 6,0. A umidade foi ajustada para $130 \%$ da capacidade de retenção de água com a adição de $34 \mathrm{~mL}$ de água deionizada por frasco. Em cada frasco, sobre o solo, foi colocada uma placa suporte com dimensões de $35 \times 29 \times 3 \mathrm{~mm}$, sendo de alburno de Pinus sp. para o cultivo de Gloeophyllum trabeum, e Cecropia sp. para o cultivo de Trametes versicolor. 
A seguir os frascos foram autoclavados a $127^{\circ} \mathrm{C}$ por 45 minutos e após o resfriamento em cada frasco foram inoculados $2 \mathrm{~mL}$ do meio de cultura contendo o micélio fragmentado. Posteriormente os frascos foram levados à incubadora $\left(26 \pm 2{ }^{\circ} \mathrm{C}\right.$ e $70 \pm 5 \%$ de umidade relativa) até o micélio cobrir completamente a placa suporte (quatro semanas). Após a colonização das placas suporte adicionou-se um corpo de prova em cada frasco.

As amostras permaneceram em contato com os fungos na incubadora por 12 semanas. Após este período foram retiradas dos frascos de ensaio. O micélio aderido foi suavemente removido e os corpos de prova foram novamente climatizados e pesados sob as mesmas condições anteriores ao teste. Por meio da diferença de massa seca inicial e final obteve-se a perda de massa e classificados segundo os critérios estabelecidos pela ASTM D 2017 (ASTM, 2005), Tabela 1.

As amostras das espécies foram avaliadas quanto ao índice de susceptibilidade ao ataque, proposto por Curling \& Murphy (2002), que relaciona a perda de massa de uma determinada espécie de interesse com a perda de massa de uma espécie de referência (Equação 1).

$I S A=\frac{P M i}{P M r} * 100$

Em que: ISA = índice de susceptibilidade ao ataque (\%); Pmi = perda de massa da espécie de interesse (\%); $\mathrm{PMr}=$ perda de massa da espécie de referência (Pinus sp. ou Cecropia sp.) ao fungo apodrecedor utilizado (\%).

Para permitir a análise estatística os dados da perda de massa em porcentagem foram transformados em arcsen[raiz(perda de massa/100)], sugerido por Steel \& Torrie (1980). Essa transformação foi necessária para permitir a homogeneidade das variâncias. Foram

Tabela 1. Classes de resistência da madeira a fungos xilófagos, segundo a ASTM D 2017 (ASTM, 2005).

Table 1. Classes of resistance of wood to rot fungi in accordance to ASTM D 2017 (ASTM, 2005).

\begin{tabular}{lcc|}
\hline Classe de resistência & $\begin{array}{c}\text { Perda de } \\
\text { Massa (\%) }\end{array}$ & $\begin{array}{c}\text { Massa } \\
\text { residual (\%) }\end{array}$ \\
\hline $\begin{array}{l}\text { Altamente } \\
\text { resistente (AR) }\end{array}$ & $0-10$ & $90-100$ \\
$\begin{array}{l}\text { Resistente (R) } \\
\begin{array}{l}\text { Moderadamente } \\
\text { resistente (MR) }\end{array}\end{array}$ & $11-24$ & $76-89$ \\
Não resistente (NR) & $>45$ & $56-75$ \\
\hline
\end{tabular}

ensaiadas 20 amostras por espécie florestal para cada fungo. Para a comparação múltipla de médias utilizou-se o teste de Tukey a 5\% de significância.

\section{RESULTADOS E DISCUSSÃO}

Ao analisar os resultados médios de perda de massa (Tabela 2) para a podridão parda (Gloeophyllum trabeum) percebe-se que para o Eucalyptus tereticornis e Eucalyptus dunnii não houve diferença estatística entre si. Da mesma forma as perdas de massa entre a Hovenia dulcis e a espécie de referência Pinus sp. não foram significativamente diferentes entre si.

A menor perda de massa ocorreu na espécie Eucalyptus robusta diferindo estatisticamente das demais madeiras. Os resultados da perda de massa do fungo de podridão banca (Trametes versicolor) indicam que a espécie Hovenia dulcis e a espécie de referência Cecropia sp. não diferiram estatisticamente entre si, porém diferiram em relação à Eucalytpus robusta, Eucalyptus tereticornis e Eucalyptus dunnii, que enquadram-se como mais resistentes ao ataque do fungo.

A menor perda de massa ocorreu na espécie Eucalyptus robusta para o fungo de podridão parda e podridão branca respectivamente, diferindo estatisticamente das demais. Percebe-se que, embora a massa específica aparente encontrada para essa espécie não foi a mais elevada, esta apresentou os melhores resultados quanto à perda de massa e classes de resistência, resultando em maior resistência ao ataque dos fungos em relação às demais espécies.

Panshin \& De Zeeuw (1980) alegaram que a massa específica, e consequentemente a porosidade, pode ser empregada como indício da durabilidade natural, e madeiras mais densas ou menos porosas oferecem maior resistência ao apodrecimento por fungos, porém Alves et al. (2006) e Quirino et al. (1982), ao analisarem a resistência natural com diferentes espécies e fungos, não observaram relação entre a massa específica e a resistência natural das madeiras, constatando que a perda de massa se deve às variações na concentração de extrativos entre as espécies, o que de fato pode explicar os resultados encontrados no presente estudo, como também afirmaram Oliveira et al. (1986), que a resistência à deterioração pode ser atribuída em grande parte à presença de taninos e outras substâncias 
Tabela 2. Valores médios de massa específica aparente a $12 \%$ de umidade, perda de massa e classificação da resistência das espécies submetidas à ação de fungos de podridão parda e branca.

Table 2. Average values of specific density at moisture $12 \%$, mass loss and resistance classification of the species under the action of brown rot and white fungi.

\begin{tabular}{|c|c|c|c|c|c|}
\hline \multirow{3}{*}{ Espécie } & \multirow{3}{*}{$\begin{array}{c}\text { Massa específica } \\
\left(\mathrm{g} \cdot \mathrm{cm}^{-3}\right)\end{array}$} & \multicolumn{4}{|c|}{ Fungo } \\
\hline & & \multicolumn{2}{|c|}{ Gloeophyllum trabeum } & \multicolumn{2}{|c|}{ Trametes versicolor } \\
\hline & & $\begin{array}{c}\text { Perda de massa } \\
(\%)\end{array}$ & $\begin{array}{c}\text { Classe de } \\
\text { resistência }^{1}\end{array}$ & $\begin{array}{c}\text { Perda de massa } \\
(\%)\end{array}$ & $\begin{array}{c}\text { Classe de } \\
\text { resistência }\end{array}$ \\
\hline $\begin{array}{l}\text { Eucalyptus } \\
\text { robusta }\end{array}$ & 0,75 & $\begin{array}{c}16,55 \mathrm{Aa} \\
(22,00)\end{array}$ & $\mathrm{R}$ & $\begin{array}{c}11,89 \mathrm{Aa} \\
(37,11)\end{array}$ & $\mathrm{R}$ \\
\hline $\begin{array}{l}\text { Eucalyptus } \\
\text { tereticornis }\end{array}$ & 0,90 & $\begin{array}{c}27,29 \mathrm{Ba} \\
(14,24)\end{array}$ & MR & $\begin{array}{c}20,81 \mathrm{Bb} \\
(22,53)\end{array}$ & $\mathrm{R}$ \\
\hline Eucalyptus dunnii & 0,88 & $\begin{array}{c}30,34 \mathrm{Ba} \\
(25,18)\end{array}$ & MR & $\begin{array}{c}32,49 \mathrm{Ca} \\
(22,35)\end{array}$ & MR \\
\hline Hovenia dulcis & 0,67 & $\begin{array}{c}47,09 \mathrm{Ca} \\
(6,98)\end{array}$ & NR & $\begin{array}{c}47,97 \mathrm{Da} \\
(10,43)\end{array}$ & NR \\
\hline Pinus sp. & & $\begin{array}{c}54,63 \mathrm{C} \\
(15,63)\end{array}$ & NR & & \\
\hline Cecropia sp. & & & & $\begin{array}{c}52,31 \mathrm{D} \\
(3,61)\end{array}$ & NR \\
\hline
\end{tabular}

Médias seguidas na vertical por uma mesma letra maiúscula ou na horizontal por uma mesma letra minúscula não diferem estatisticamente (Tukey p > 0,05); $\mathrm{R}=$ Resistente; $\mathrm{MR}=$ Moderadamente resistente; $\mathrm{NR}=$ Não resistente; entre parênteses Coeficiente de Variação. ${ }^{1}=$ ASTM D 2017 (ASTM, 2005).

fenólicas complexas, presentes na madeira, as quais são tóxicas a determinados fungos xilófagos. Dessa forma, pode-se sugerir que Eucalyptus robusta tem influência significativa, dessas variáveis, na sua durabilidade natural frente à ação de fungos xilófagos.

Os valores médios da perda de massa, obtidos para as espécies de eucaliptos consideradas neste trabalho, foram inferiores aos obtidos por Modes (2010), realizada com madeira de cerne de Eucalyptus grandis com aproximadamente 25 anos, submetida ao apodrecimento acelerado em laboratório, após 12 semanas de ensaio, em que se observou uma perda de massa da madeira de $57,74 \%$ e $41,46 \%$ para os fungos Trametes versicolor e Gloeophyllum trabeum, respectivamente.

Na comparação da perda de massa média observada nas madeiras submetidas à ação dos diferentes fungos, constatou-se diferença estatística somente para a espécie Eucalyptus tereticornis. Essa diferença talvez possa ser explicada pelas diferentes necessidades dos fungos em relação às composições de cada espécie florestal. Sobre essa questão, Schmidt (2006) relata que as preferências por certas madeiras relacionam-se com as características e necessidades nutricionais de cada organismo xilófago. Com o mesmo enfoque, Eaton \& Hale (1993) comentaram que a resistência natural da madeira está condicionada às vias de acesso para os fungos e à composição química das mesmas, sendo esta uma característica que varia substancialmente entre espécies e até mesmo dentro da mesma árvore.

De acordo com as classes de resistência em função da perda de massa, segundo a ASTM D 2017 (ASTM, 2005) a madeira de Eucalyptus robusta foi resistente tanto para o fungo de podridão parda quanto para podridão branca. Para a madeira de Eucalyptus tereticornis a podridão parda foi classificada como moderadamente resistente, já para a podridão branca a madeira foi resistente. As amostras provindas de Eucalyptus dunnii demonstraram-se semelhantes para ambos os fungos, quanto à perda de massa, enquadrando-se como madeira moderadamente resistente. Comportamento semelhante à Hovenia dulcis, porém esta classificou-se como não resistente.

Para as espécies de referência, os valores médios de perda de massa foram de 54,63\% para Pinus sp., proporcionada pelo fungo Gloeophyllum trabeum, e 52,31\% para a Cecropia sp. quando submetida à ação do fungo Trametes versicolor. Os valores encontrados após as 12 semanas de ensaio foram superiores ao valor de 50,0\% estabelecido pela ASTM D-2017 (ASTM, 2005), evidenciando que as culturas fúngicas apresentavam bom 
vigor e que as condições de ensaios foram adequadas. Oliveira et al. (2005) encontraram o valor médio de $38,0 \%$ de perda de massa para a espécie de referência Pinus elliotti, com mínimo de $21,1 \%$ e máximo de $55,3 \%$, comprovando a validade do ensaio, porém o valor médio foi abaixo do encontrado no presente estudo.

Nota-se que em relação ao fungo de podridão parda a madeira de Eucalyptus tereticornis e Eucalyptus dunnii não diferiram estatisticamente entre si, porém quanto ao fungo de podridão branca verifica-se que todas as espécies diferiram estatisticamente entre si, o que comprova as diferenças das necessidades de cada organismo afetando a durabilidade da madeira, como comenta Lepage (1986), que a madeira, por ser um material de durabilidade natural variável, pode apresentar diferenças quanto à sua resistência a fungos apodrecedores.

Comparando-se o índice de susceptibilidade (Tabela 3) ao ataque de cada fungo nas espécies nota-se que não houve diferença estatística entre as mesmas. Conforme explicam Curling \& Murphy (2002), um índice de susceptibilidade acima de 100 denota amostras menos resistentes que a madeira de referência e índice abaixo de 100, mais resistente que a referência. Verifica-se que neste estudo todas as espécies apresentaram índices abaixo de 100 para os dois fungos ensaiados, indicando que as espécies estudadas apresentaram valores aceitáveis, sendo mais resistente ao ataque dos fungos em relação às espécies de referência Pinus sp. Cecropia sp. Sugere-se a condução de novos estudos com o objetivo de avaliar o efeito da composição química da madeira na sua resistência natural.

Tabela 3. Valores de índice de susceptibilidade ao ataque \% (ISA).

Table 3. Values of index of susceptibility of to attack $\%$ (ISA).

\begin{tabular}{|ccc|}
\hline Espécie & $\begin{array}{c}\text { Gloeophyllum } \\
\text { trabeum }\end{array}$ & $\begin{array}{c}\text { Trametes } \\
\text { versicolor }\end{array}$ \\
\hline $\begin{array}{c}\text { Eucalyptus } \\
\text { robusta }\end{array}$ & $30,29 \mathrm{Aa}$ & $22,72 \mathrm{Aa}$ \\
\hline $\begin{array}{c}\text { Eucalyptus } \\
\text { tereticornis }\end{array}$ & $49,96 \mathrm{Ba}$ & $39,78 \mathrm{Ba}$ \\
\hline Eucalyptus dunnii & $55,54 \mathrm{Ba}$ & $62,11 \mathrm{Ca}$ \\
\hline Hovenia dulcis & $86,20 \mathrm{Ca}$ & $91,71 \mathrm{Da}$ \\
\hline
\end{tabular}

Médias seguidas na vertical por uma mesma letra maiúscula ou na horizontal por uma mesma letra minúscula não diferem estatisticamente (Tukey p $>0,05$ ).

\section{CONCLUSÕES}

A massa específica aparente não influi diretamente na durabilidade natural das espécies avaliadas.

A madeira de Eucalyptus robusta foi classificada como resistente e a de Hovenia dulcis como não resistente ao ataque dos fungos Gloeophyllum trabeum e Trametes versicolor.

O emprego do índice de susceptibilidade à ação de fungos xilófagos na madeira evidencia que as espécies estudadas apresentam valores aceitáveis, sendo mais resistentes ao ataque dos fungos em relação às espécies de referência.

\section{STATUS DA SUBMISSÃO}

Recebido: 23 jul., 2014

Aceito: 17 fev., 2015

\section{AUTOR(ES) PARA CORRESPONDÊNCIA}

\section{Douglas Edson Carvalho}

Departamento de Engenharia e Tecnologia Florestal, Centro de Ciências Florestais e da Madeira, Universidade Federal do Paraná UFPR, Av. Pref. Lothário Meissner, 900, Jardim Botânico - Campus III, CEP 80210-170, Curitiba, PR, Brasil e-mail: douglasedsoncarvalho@gmail.com

\section{REFERÊNCIAS}

Alves MVS, Costa AF, Espig DS, Vale AT. Resistência natural de seis espécies de madeiras da região amazônica a fungos apodrecedores, em ensaio de laboratório. Ciência Florestal 2006; 16(1): 17-26.

American Society for Testing and Materials - ASTM. ASTM D-2017: standard method of accelerated laboratory test of natural decay resistance of woods. Philadelphia; 2005. 5 p. Annual Book of ASTM Standard.

Barillari CT. Durabilidade da madeira do gênero Pinus tratada com preservantes: avaliação em campo de apodrecimento [dissertação]. Piracicaba: Escola Superior de Agricultura Luiz de Queiroz; 2002.

Costa AF. Processos práticos de tratamento de madeiras para o meio rural. Brasília: Editora Universidade de Brasília; 2003.

Curling SF, Murphy RJ. The use of the Decay Susceptibility Index (DSI) in the evaluation of biological durability 
tests of wood based board materials. Holz als Roh- und Werkstoff 2002; 60(3): 224-226. http://dx.doi.org/10.1007/ s00107-002-0284-2.

Eaton RA, Hale MDC. Wood: decay, pests and protection. London: Chapman \& Hall; 1993.

Lepage ES. Manual de preservação de madeiras. São Paulo: IPT; 1986.

Modes KS. Efeito da retificação térmica nas propriedades físico-mecânicas e biológica das madeiras de Pinus taeda e Eucalyptus grandis [dissertação]. Santa Maria: Universidade Federal de Santa Maria; 2010.

Oliveira AMF, Lelis AT, Lepage ES, Lopez GAC, Oliveira LCS, Canedo MD et al. Agentes destruidores da madeira. In: Lepage ES, coordenadores. Manual de preservação de madeiras. São Paulo: IPT; 1986.

Oliveira JT, Tomasello M, Silva JC. Resistência natural da madeira de sete espécies de eucalipto ao apodrecimento. Revista Árvore 2005; 29(6): 993-998. http://dx.doi. org/10.1590/S0100-67622005000600019.

Paes JB. Resistência natural de madeira de Corymbia maculata (Hook.) K.D. Hill \& L.A.S. Johnsos a fungos e cupins xilófagos, em condições de laboratório. Revista Árvore 2002; 26(6): 761-767. http://dx.doi.org/10.1590/ S0100-67622002000600012.

Panshin AJ, De Zeeuw C. Text book of wood technology. 4th ed. New York: McGraw Hill; 1980.

Quirino WF, Nakamura RM, Lisboa CDJ, Brito CT. Resistência da madeira de quatro espécies florestais ao ataque do fungo Trichoderma viride Pers et S. F. Gray. Brasília: IBDF/LPF; 1982.

Santini, EJ. Biodeterioração e preservação da madeira. Santa Maria: UFSM/CEPET/FATEC; 1988.

Schmidt O. Wood and tree fungi. biology, damage, protection and use. Berlin: Springer-Verlag; 2006.

Steel RGD, Torrie JH. Principles and procedures of statistics; a biometrical approach. 2nd ed. New York: McGraw Hill; 1980 .

Walker JCF. Basic wood chemistry and cell wall ultrastructure. Primary wood processing: principles and practice. Dordrecht: Springer, 2006. 